Научная статья

УДК 338

DOI: $10.17213 / 2075-2067-2021-5-86-97$

\title{
ИСКУССТВЕННЫЙ ИНТЕЛЛЕКТ И ЕГО МЕСТО В РАЗВИТИИ МАЛОГО БИЗНЕСА
}

\author{
Айдарбек Токторович Гыязов ${ }^{1 凶}$, Муса Мурзапарович Усонов ${ }^{2}$, \\ Хабибулла Кушакович Тагаев ${ }^{3}$ Шукурбек Илиясович Кадыров \\ 1, 2, 3, 4 Баткенский государственный университет, Баткен, Кыргызстан \\ ${ }^{1}$ aziret-81@mail.ru ${ }^{凶}$, ORCID: 0000-0002-8200-7438 \\ ${ }^{2}$ musabos114@mail.ru, ${ }^{3}$ tagaev_69@mail.ru, ${ }^{4}$ kadyrov.sh78@gmail.com
}

Аннотация. Цель исследования состоит в том, чтобы рассмотреть искусственный интеллект, его место и роль в развитии малого бизнеса.

Методологическая база исследования представляет собой совокупность теоретических, эмпирически-прикладных и нормативно-правовых положений в области изучения искусственного интеллекта и его влияния на экономику.

Результаты исследования. В статье исследована роль искусственного интеллекта в малом и среднем бизнесе, предложена разработанная авторами компьютерная программа с применением реккурентной модели малого предприятия, которая позволяет делать прогноз показателей эффективности деятельности сельскохозяйственного предприятия в краткосрочном и долгосрочном периоде.

Перспективы дальнейших исследований заключаются в последующем изучении искусственного интеллекта на экономику.

Ключевые слова: искусственный интеллект, малый и средний бизнес, управление, сельское хозяйство, реккурентная модель, компьютерная программа

Для цитирования: Гыязов А. Т., Усонов М. М., Осмонов З. А., Кадыров Ш. И. Искусственный интеллект и его место в развитии малого бизнеса // Вестник ЮжноРоссийского государственного технического университета. Серия: Социально-экономические науки. 2021. T. 14, №5. C. 86-97. http://dx.doi.org/10.17213/2075-2067-2021-5-86-97.

Original article

\section{ARTIFICIAL INTELLIGENCE AND ITS PLACE IN THE DEVELOPMENT OF SMALL BUSINESS}

\author{
Aidarbek T. Giyazov ${ }^{1 \bowtie}$, Musa M. Usonov', \\ Khabibulla K. Tagaev ${ }^{3}$, Shukurbek I. Kadyrov ${ }^{4}$ \\ 1, 2, 3, ${ }^{4}$ Batken State University, Kyrgyzstan, Batken \\ ${ }^{1}$ aziret-81@mail.ru ${ }^{\bowtie}$, ORCID:0000-0002-8200-7438 \\ 2musabos114@mail.ru, ${ }^{3}$ tagaev_69@mail.ru, ${ }^{4}$ kadyrov.sh78@gmail.com
}

(C) Гыязов А. Т., Усонов М.М., Тагаев Х.К., Кадыров Ш.И., 2021 
Abstract. The purpose of the study is to consider artificial intelligence, its place and role in the development of small business.

The methodological basis of the research is a set of theoretical, empirical-applied and regulatory provisions in the field of studying artificial intelligence and its impact on the economy.

The results of the study. The article examines the role of artificial intelligence in small and medium-sized businesses, offers a computer program developed by the authors using a competitive model of a small enterprise, which allows you to make a forecast of the performance indicators of an agricultural enterprise in the short and long term.

The prospects for further research lie in the further study of artificial intelligence on the economy.

Keywords: artificial intelligence, small and medium business, management, agriculture, recurrent model, computer program

For citation: Giyazov A. T., Usmanov M. M., Osmanov Z. A., Kadyrov Sh. I. Artificial intelligence and its place in the development of small business // Bulletin of the South Russian State Technical University. Series: Socio-economic Sciences. 2021; 14(5): 86-97. (In Russ.). http:// dx.doi.org/10.17213/2075-2067-2021-5-86-97.

Введение. Аланом Тюрингом в 1950 году была опубликована работа ${ }^{1}$, в которой он высказал предположение о возможном создании «мыслящих» машин. Это можно считать одним из первых упоминаний об искусственном интеллекте. Приблизительно 70 лет назад появилось первое определение искусственного интеллекта (ИИ), которое в течение следующих десятилетий расширялось и дополнялось со стороны многих ученых и исследователей $[1,5]$.

На сегодняшний день, на наш взгляд, актуально следующее определение искусственного интеллекта: «ИИ - это наука и технология разработки компьютерных систем, которые способны выполнить задачи, решаемые обычно человеческим интеллектом, например: понимание языка, память, обучение, способность решать математические и логические задачи, способность распознавать образы и другие».

До начала 80-х годов искусственный интеллект не находил широкого применения в мире предпринимательства. Сейчас искусственный интеллект изменяет лицо бизнеса. ИИ уже давно стал реальностью, а не кон- цепцией будущего. Большинство компаний, вплоть от гигантов технологий вроде Apple, Amazon и Google до клиентоориентированных Starbucks и Uber применяют ИИ для совершенствования сервиса клиентов ${ }^{2}$. Возникает вопрос: только ли крупным корпорациям может быть полезен ИИ, или малый бизнес (например, в Кыргызской Республике) тоже может обратить на него своё внимание? По нашему мнению, ответ однозначен - малым предприятиям в Кыргызстане следует внедрить в свою деятельность ИИ как можно быстрее, ведь это даст большие конкурентные преимущества и повысит эффективность деятельности, что было доказано данным исследованием.

В данный момент проведенное нами научное исследование имеет большую актуальность и значение, так как соответствует направлению развития экономики Кыргызстана и страны в целом: Президент Кыргызской Республики С.Ш. Жээнбеков объявил 2019-й год годом развития регионов и цифровизации страны $^{3}$. Намечается внедрение цифровых технологий в сектор образования и здравоохранения, финансово-кредитный сектор, от-

1 Алан Тюринг. Википедия [Электронный ресурс]. URL: https://en.wikipedia.org/wiki/Alan_Turing (дата обращения: 12.11.18).

2 Джон Свонсигер, CEO Manta. Как небольшие компании могут получить выгоду от использования ИИ в бизнесе [Электронный ресурс]. URL: https://rb.ru/story/small-business-AI/.

3 Издание «Спутник»: Президент КР объявил 2019-й год годом развития регионов и цифровизации страны [Электронный ресурс]. URL: https://sptnkne.ws/kzjn. 
расли туризма, коммуникаций до 2023 года ${ }^{4}$. Для осуществления поставленной президентом задачи необходимо сначала рассмотреть область и примеры применения искусственного интеллекта.

Результаты исследования. Starbucks является отличным примером компании, которая применяет ИИ при обслуживании своих потребителей. Виртуальный облачный помощник Alexa содержит функцию Starbucks Reorder, позволяющую сделать заказ с помощью голосовой команды (например, попросить приготовить стандартный кофе, проверить баланс карты и т.д.). Практика показывает, что крупные компании используют ИИ в основном для рекламы, а малые предприятия реализуют различные опции, полезные для потребителей.

Привыкание клиентов к решениям с использованием ИИ приведет к тому, что они будут ожидать того же от малых компаний. Но есть некоторые нюансы применения искусственного интеллекта в малом бизнесе. Малым предприятиям не следует приступать к работе с ИИ без конкретного плана. Необходимым условием является определение специфики применения искусственного интеллекта.

Допустим, для мебельного магазина возможно использование ИИ для изучения предсказательной (предиктивной) аналитики, для снижения неэффективности кадров. Для владельцев пиццерии и службы доставки, возможно, будет интересна идея использования беспилотных дронов или авто. Правильно поставив цели с учетом специфики предприятия, предприниматели получают возможность разработки четкого плана мер по их достижению.

Даже если малое предприятие не готово пока применять искусственный интеллект, важно следить за рынком, знать о новейших разработках и достижениях науки в сфере ИИ, способных послужить компании, и наблюдать за действиями конкурентов в этой области. Активно изучая ИИ, малые предприятия готовятся к использованию его элементов в целях оптимизации бизнес-процессов, повышения качества обслуживания. Превра- щение небольшого предприятия в солидную компанию, ориентирующуюся в первую очередь на работу с данными, возможно, проще, чем кажется. Для доказательства мы предложим несколько направлений для использования ИИ в небольшой компании.

1. CRM-сuстемы. CRM-системы разработаны для сбора информации о покупателях, приходящей через телефонные звонки, электронную почту, из социальных сетей. Отделу продаж предоставляется информация для управления взаимодействиями с имеющимися или потенциальными клиентами. Таким образом, автоматизируется маркетинг и lead generation - маркетинговая тактика, которая ориентирована на поиск клиентов, имеющих определённые контактные данные. CRM-приложения помогают компаниям в анализе потребительских настроений, получая данные из постов в социальных сетях и обзоров, публикуемых клиентами, записей их телефонных разговоров, электронных писем. Они также оценивают отзывы покупателей, корректируя маркетинговую активность соответствующим образом. Мелкие компании благодаря CRM с поддержкой искусственного интеллекта могут автоматически получить больше информации из данных о клиенте, повысить эффективность отделов маркетинга и продаж, а также уровень удовлетворенности покупателей.

2. Искусственный интеллект для маркетинговой деятельности. Высокий уровень компетентности является необходимым условием эффективного управления маркетинговым бюджетом. Однако это влечет за собой дополнительные издержки. Благодаря решениям на основе искусственного интеллекта небольшие предприятия могут распоряжаться эффективно весьма скромным бюджетом. Малый бизнес может доверить ведение маркетинговых кампаний ИИ-платформам, управляющим маркетинговыми действиями через несколько каналов (например, Adwords, Facebook, Bing), анализирующим эффективность рекламы и выдвигающим обоснованные предложения относительно наилучшего распределения бюджета с точки зрения РРС (оплаты за клик).

4 Издание медиа группы Европа «Новости. Кg» [Электронный ресурс]. URL: ttp://novosti.kg/2019/01/2019god-v-kyrgyzstane-obyavlen-godom-razvitiya-regionov-i-tsifrovizatsii-strany/. 
3. Интеллектуальные решения для обслуживания клиентов. Обслуживание и поддержка клиентов - ключевые составляющие сервиса компании, необходимые для удержания покупателей и сохранения высокого уровня удовлетворенности аудитории. Но качество обслуживания может снизиться, если сотрудники вынуждены выполнять однообразные и рутинные задачи, вместо того чтобы сосредоточиться на создании уникального опыта для потребителя. Чтобы повысить эффективность сотрудников, малые компании могут внедрить ИИ во внутреннюю службу поддержки. Например, такие решения, как Digital Genius могут предлагать ответы или генерировать их автоматически, а также классифицировать сообщения, чтобы оперативно направлять их в нужный отдел или команду, высвобождая тем самым время сотрудников службы поддержки для решения вопросов, требующих участия человека. Применив решения ИИ, малый бизнес может значительно уменьшить среднее время обработки заявки, а также автоматизировать ответы на повторяющиеся вопросы, приблизившись к конечной цели - увеличению уровня удовлетворенности сотрудников и клиентов.

4. Использование искусственного интеллекта в конкурентной борьбе. Для сохранения конкурентоспособности и быстрого реагирования на тенденции рынка необходимо владеть информацией о конкурентах. Для отслеживания их стратегии можно использовать инструменты для конкурентного анализа на основе ИИ. Это программы, умеющие отслеживать активность конкурентных компаний по разным каналам (на сайтах или на страницах социальных сетей), изменения в ценах, в рассылках писем или PR-сообщениях. ИИ обеспечивает небольшим компаниям лучшее понимание текущей ситуации и стратегии конкурентов. Кроме того, серьезные аналитические инструменты позволяют быстро определять пробелы в схемах конкурентов, их слабые и сильные стороны. Можно использовать эти знания для разработки и исправления собственной стратегии, конкуренты никогда не смогут неожиданно нанести удар.
5. Программы и разработки на основе искусственного интеллекта. Небольшие компании могут использовать готовые программные разработки на любом этапе бизнеса, где требуется работа с данными. Применение новейших алгоритмов для анализа настроений (Monkey Learn) и желаний покупателей, расчета прогнозов и составления классификации даст малым предприятиям возможность быстро извлечь нужные сведения. Применять и извлекать ключевую информацию из Google Sheets, документов CSV или Excel возможно вовсе без программирования. Платформа Monkey Learn может быть использована для анализа обзоров продукта и их последующего преобразования в отчеты, содержащие необходимые сведения. Это экономит средства и время, которые нужны малому предприятию для обработки информации.

В настоящий момент рынок ИИ бурно развивается, и у малых предприятий много возможностей строить свою стратегию с использованием ИИ. Использование инструментов с простым интерфейсом и встроенным функционалом машинного обучения вместо найма специалистов по маркетингу и анализу данных сэкономит малым компаниям время и средства, вместе с тем дав возможность быть конкурентоспособными в условиях новой рыночной экономики, основанной на работе с данными ${ }^{5}$.

Обсуждение результатов. Кыргызская Республика является горной страной, где преобладает аграрный сектор, более $65 \%$ населения проживает в сельской местности. Доля занятого в аграрном производстве населения в общей численности занятых по республике составляет $34 \%$, при этом показатели эффективности в сфере малого бизнеса оставляют желать лучшего. Кыргызстан нуждается в создании и развитии малого предпринимательства, особенно в секторе сельского хозяйства. Стоит острая необходимость в повышении эффективности управления существующими и создающимися предприятиями, и самым действенным инструментом в этом для них может стать искусственный интеллект. Для эффективного управления требуется адекват-

5 Олег Солозобов. 5 выгод от применения ИИ в малом бизнесе [Электронный ресурc]. URL: https://8d9.ru/5vygod-ot-primeneniya-iskusstvennogo-intellekta-v-malom-biznese-uzhe-segodnya | 03.12.2017. 
ная оценка эффективности и принятие оптимальных управленческих решений для повышения ее уровня. При этом важно провести оценку не только критериев эффективности деятельности предприятия, но и потенциальных способов достижения заданного уровня эффективности. Процесс управления с оптимальной структурой является одним из путей повышения результативности. Оптимизация структуры управления, по сути, предполагает поиск эффективного варианта с минимальными издержками на управление.

Среди различных методов оценки нами рассмотрены в качестве основы создания оптимального варианта управления рекуррентные модели, опирающиеся на погодичный пересчет показателей эффективности деятельности, т.е. перерасчет данных за текущий период по показателям прошлого периода. Реккурентное моделирование, как правило, использует субъекты, у которых развитие имеет цикличный характер. Один цикл при этом обозначается $\Delta t$ и называется шагом итерации по времени.

В качестве объекта исследования нами изучен сельскохозяйственный кооператив. Сезонный характер деятельности сельскохозяйственных предприятий позволяет взять за 1 цикл период в один год, поэтому выполнено рекуррентное моделирование с шагом по времени $\Delta t=1$ год.

Управленческий процесс в сельскохозяйственном кооперативе охватывает чередование двух взаимосвязанных событий:

1) собственно управление (издержки на управление);

2) экономический отклик на управленческие действия (объем продукции, доходы, прибыль и т.п.).

Рекуррентная модель учитывает чередование данных этапов, отражая взаимосвязь показателей двух идущих подряд периодов: $(i)$ - текущий год, $(i-1)$ - прошлый год [4]. При этом повторяются этапы управления и отклика на управленческие действия для каждого периода:

1) на этапе управления определяются параметры управления $3 O T_{\text {i, }} 3 C M_{\text {i }}$, 3T (задаются параметры для оценки различных вариантов управления, прогнозные показатели развития предприятия рассчитываются на основе показателей прошлых лет);
2) на этапе реакции на управленческие воздействия прогнозируются показатели эффективности $Ч \Pi_{\mathrm{i}}, B P_{\mathrm{i}}, O \Pi_{\mathrm{i}}$ на базе задаваемых параметров управления $3 O T_{\mathrm{i}}, 3 C M_{\mathrm{i}}$, $3 T_{\mathrm{i}}$, и показателей прошлого года $Ч \Pi_{\mathrm{i}-1}, B P_{\mathrm{i}-1}$ c учетом макроэкономических показателей ИП ${ }_{\mathrm{i}-1}$, ЭДС $\mathrm{i}-1_{1}$ за прошлый год.

Рекуррентные модели составляются на основе рекурсивных формул, позволяющих определить показатели за $i$-й год по показателям за $i-1$-й год.

Предлагаемую нами реккурентную модель развития сельскохозяйственного кооператива отразим на графике (рисунок 1).

Для упрощения прогноза данных об эффективности деятельности исследуемого предприятия на заданный период мы разработали пакет прикладных программ в приложении Borland Delphi 7, используя язык программирования Object Pascal (рисунок 2). В программу введены рекурсивные формулы и заданы первичные данные. Используя данную программу, можно спрогнозировать эффективность предприятия на 20 лет вперед, a также для наглядности составить графики рядов динамики. Варьируя исходные параметры 3OT, 3CM, 3T, OЧ в ходе компьютерных экспериментов, проводимых с помощью программы, и проводя мониторинг изменений показателей эффективности ЧП, $В Р$, OП, можно будет найти наиболее оптимальный алгоритм управления предприятием с максимальным уровнем эффективности.

Здесь следует отметить, что с увеличением периода прогнозирования возрастает степень точности прогнозных данных.

Мы считаем, что предложенная нами модель является универсальной и адаптивной и предоставляет данные по широкому спектру деятельности предприятий об эффективности управления, способствуя оптимизации управленческого процесса.

С помощью рекуррентного моделирования можно будет имитировать деятельность кооператива за 10-20 лет в условиях стабильности макроэкономических факторов (рисунок 3).

График отражает наиболее естественные значения выручки от реализации продукции, объема выпуска продукции и чистой прибыли кооператива за 2014-2018 годы. При этом принимаются во внимание специфи- 
ческие особенности организации и управления производством, управления персоналом сельхозкооператива с учетом типичных макроэкономических условий. Посредством рекуррентного моделирования проводится краткосрочное (на ближайшую перспективу) и долгосрочное (на 10-20 лет вперед) прогнозирование эффективности деятельности сельскохозяйственного кооператива.

С использованием рекуррентной модели определены прогнозные значения показателей эффективности ЧП, ВР, ОП, которые представлены в таблице 1.
Так, согласно модели прогнозные значения исследуемых показателей на 2015 год составили:

- ЧП ${ }_{2015}=3756$ тыс. сомов;

- $B P_{2015}=20104$ тыс. сомов;

$-O \Pi_{2015}=12570$ тыс. сомов.

Погрешность прогноза на год вперед равна $\pm 15 \%$ или $Ч \Pi_{2015}=3756 \pm 563$ тыс. сомов; $\quad B P_{2015}=20104 \pm 3016$ тыс. сомов; $O \Pi_{2015}=12570 \pm 1886$ тыс. сомов [1].

Уровень точности прогноза определяется на этапе анализа взаимозависимости показателей за предыдущие годы и зависит от спе-

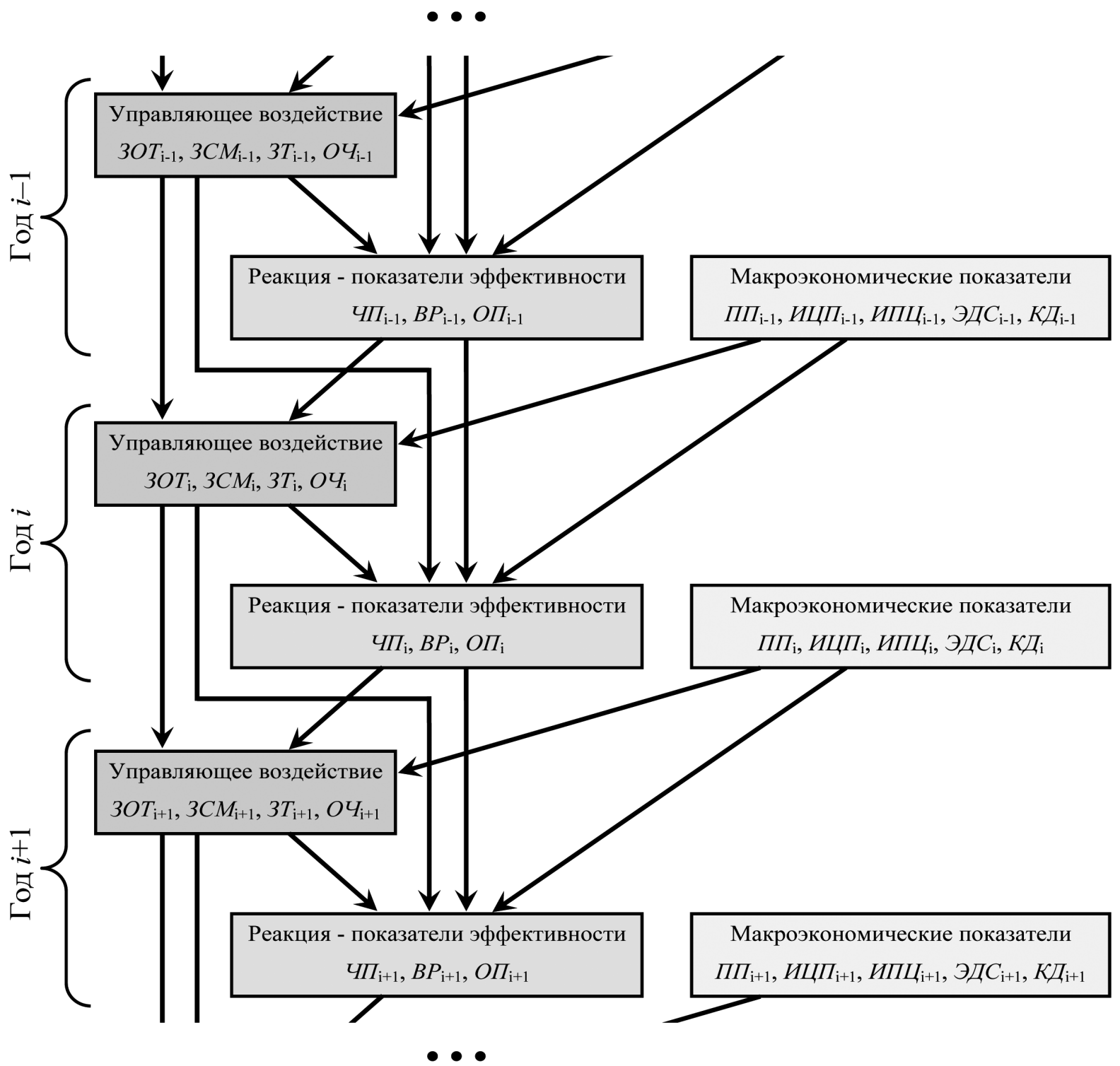

Рис. 1. Рекуррентная модель оптимизации управления сельхозкооперативом (составлено авторами)

Fig. 1. Recurrent model of optimization of agricultural cooperative management (compiled by the authors) 


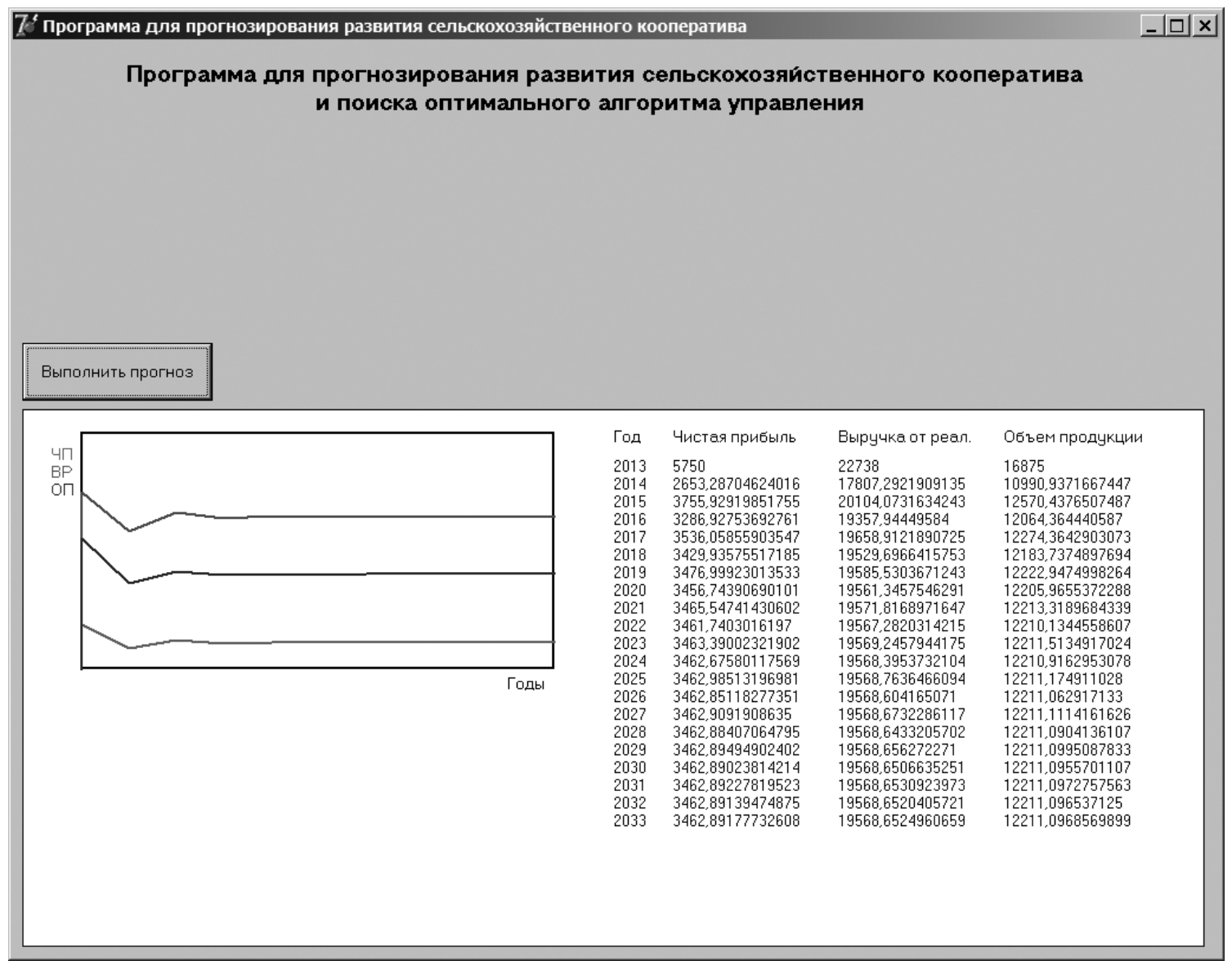

Рис. 2. Программа для прогнозирования показателей эффективности сельхозкооператива и поиска оптимального алгоритма управления (составлено авторами)

Fig. 2. A program for predicting the efficiency indicators of an agricultural cooperative and searching for the optimal control algorithm (compiled by the authors)

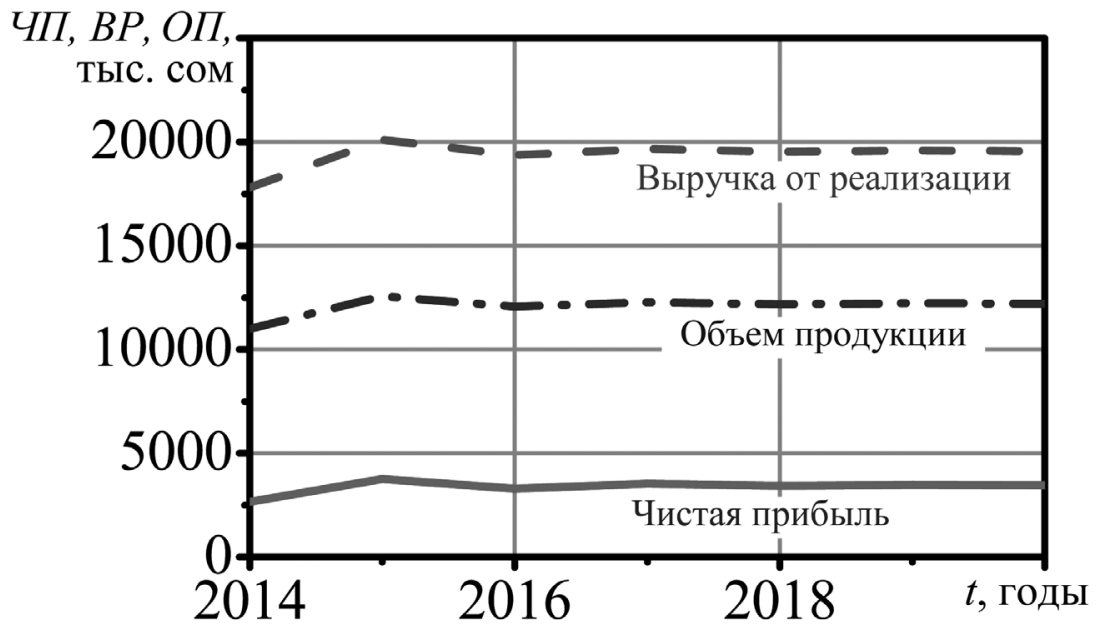

Рис. 3. Динамика изменения показателей эффективности сельхозкооператива (составлено авторами)

Fig. 3. Dynamics of changes in the efficiency indicators of the agricultural cooperative (compiled by the authors) 
цифики предприятия. Так, прогнозные показатели кооператива за 2015-2016 годы являются более точными, прогнозированием за следующие 3 года определены тенденции его развития, прогноз с ошибкой аппроксимации до 15-25\%. Иногда даже знание тенденции развития помогает руководителям осуществить долгосрочное планирование. С помощью рекуррентной модели создается имитация развития субъекта предпринимательства, сравниваются алгоритмы изменения показателей эффективности под влиянием различных событий, таких как девальвация сома, изменение импорта и экспорта, ВВП и других макроэкономических показателей [1].
В качестве примера нами построена модель расчета влияния изменений показателей ПП, ИЦП, ИПЦ, ЭДС, КД в пределах $\pm 20 \%$ (рисунок 4).

В компьютерной программе был использован генератор случайных чисел, подчиняющийся равномерному закону распределения. График показывает, что в данном случае находится в состоянии флуктуации и чистая прибыль, но в целом предприятие реагирует на внешние условия оперативно, обеспечивая ежегодно чистую прибыль от 3200 до 3800 тыс. сомов, и его состояние болееменее стабильно. В качестве средств управления исследуемым кооперативом мы взяли

Таблица 1 Table 1

\section{Прогноз показателей эффективности исследуемого предприятия [1] Forecast of performance indicators of the studied enterprise [1]}

\begin{tabular}{|c|c|c|c|c|}
\hline Год & $\begin{array}{c}\text { Чистая прибыль, } \\
\text { тыс. сом }\end{array}$ & $\begin{array}{c}\text { Выручка } \\
\text { от реализации, } \\
\text { тыс. сом }\end{array}$ & $\begin{array}{c}\text { Объем продаж, } \\
\text { тыс. сом }\end{array}$ & $\begin{array}{c}\text { Оценка } \\
\text { доверительного } \\
\text { интервала }\end{array}$ \\
\hline 2015 & 3756 & 20104 & 12570 & $\pm 15 \%$ \\
\hline 2016 & 3287 & 19358 & 12064 & $\pm 25 \%$ \\
\hline 2017 & 3536 & 19659 & 12274 & $\pm 33 \%$ \\
\hline 2018 & 3430 & 19530 & 12184 & $\pm 38 \%$ \\
\hline 2019 & 3477 & 19586 & 12223 & $\pm 41 \%$ \\
\hline
\end{tabular}

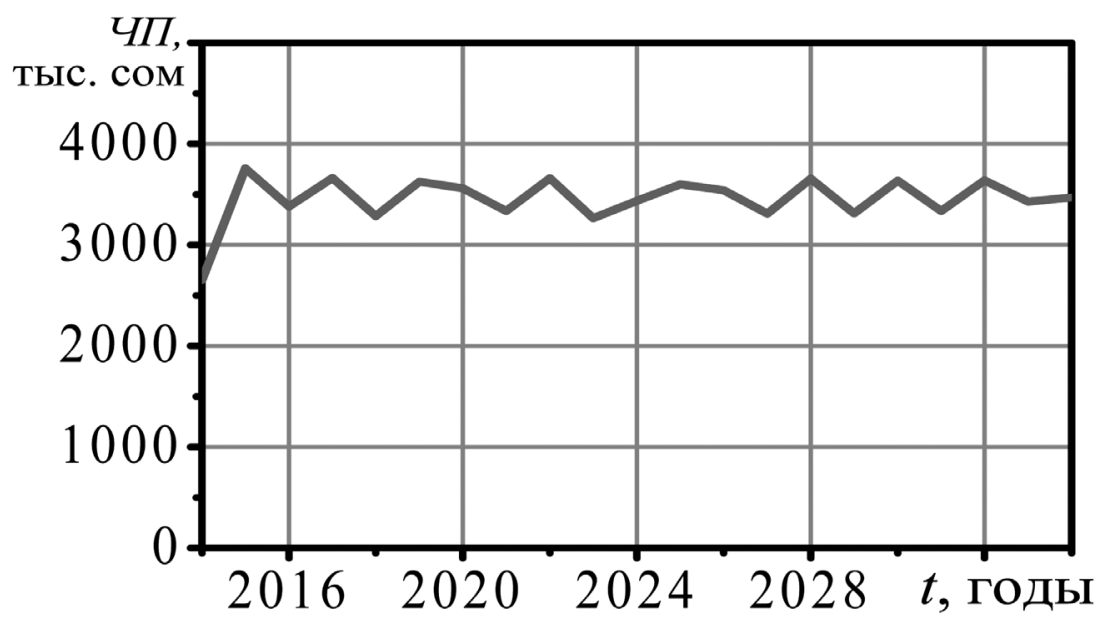

Рис. 4. Изменение чистой прибыли сельхозкооператива при случайном изменении макроэкономических показателей за определенное время

Fig. 4. Change in the net profit of an agricultural cooperative with a random change in macroeconomic indicators over a certain period of time 


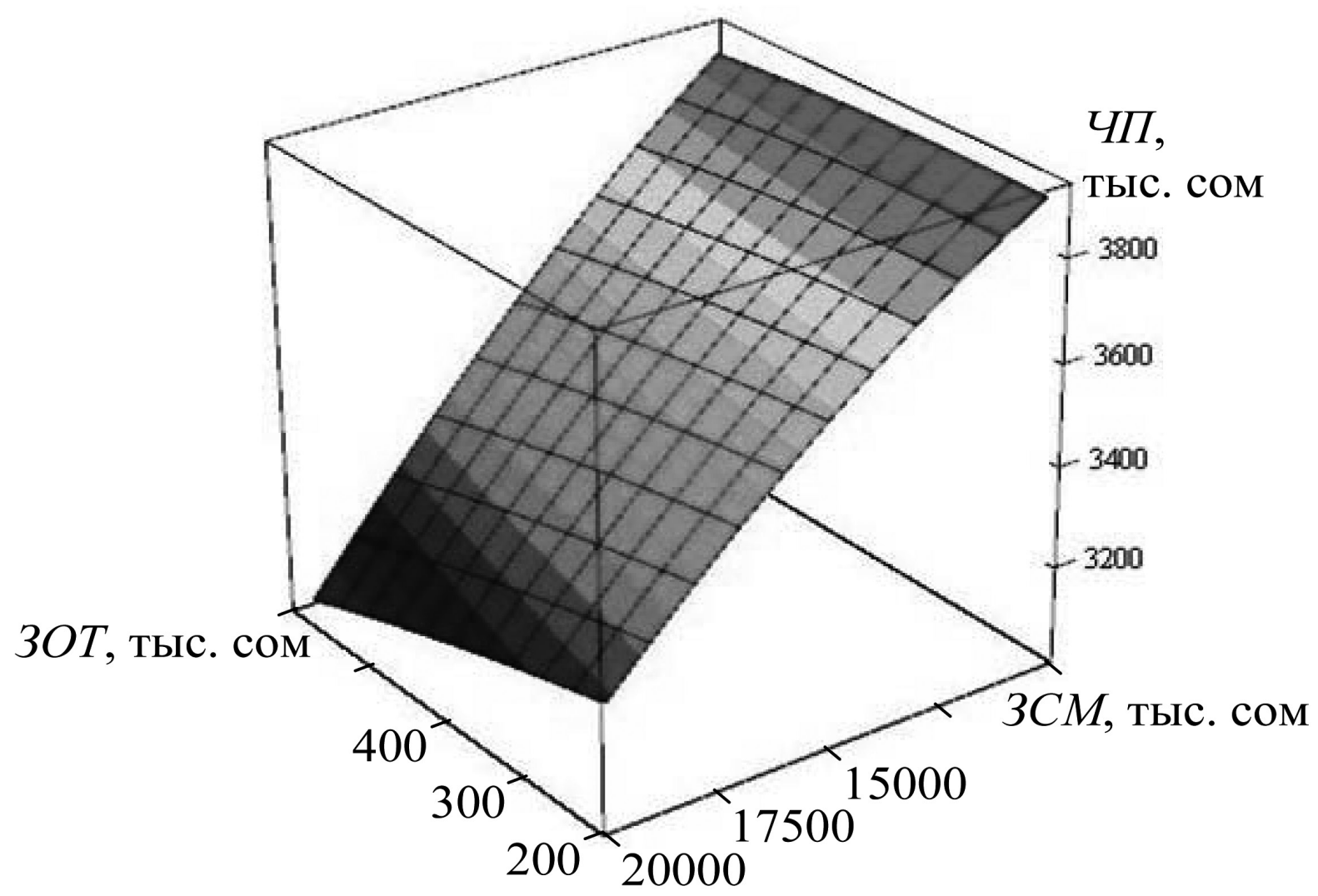

Рис. 5. Зависимость чистой прибыли от уровня $3 O T$ и $3 С M$

Fig. 5. The dependence of net profit on the level of ZOT and ZSM

параметры затрат на оплату труда (3OT), затраты на сырье и материалы (3CM) и затраты на топливо и ГСМ (3T). С помощью $30 T$ можно управлять качеством работы сотрудников, их заинтересованностью в повышении эффективности. ЗСМ помогают в управлении объемом и качеством выпускаемой продукции. Управление $3 T$ обеспечивает своевременность доставки сырья, материалов и готовой продукции.

Применением рекуррентной модели можно оценить влияние $3 O T, 3 C M$ и $3 T$ на эффективность кооператива с целью тактического и стратегического управления. В рамках решения задачи тактического управления определяется уровень $3 O T, 3 C M$ и $3 T$ в текущем году, который обеспечил бы максимальный уровень ЧП, ВР, ОП. В процессе стратегического управления необходимо выявить тенденции изменения затрат, то есть найти такие функции $3 O T(t), 3 C M(t)$ и $3 T(t)$, при которых показатели ЧП, $B P$, ОП или их сумма за несколько лет будут как можно большими.
На примере сельскохозяйственного кооператива покажем выполнение рекуррентного моделирования зависимости чистой прибыли от сумм затрат на оплату труда, сырье и материалы ЧП $(3 O T, 3 C M)$. Для этого созданы модели развития кооператива в результате проведения компьютерных экспериментов, при которых $30 T$ изменяется в диапазоне 200, 400, 600 тыс. сомов, а 3CM - 10000, 15000, 20000 тыс. сомов (рисунок 5).

На графике функции ЧП (3OT, ЗСM) видна обратная зависимость чистой прибыли от затрат на сырье и материалы и независимость от затрат на оплату труда, т.е. увеличение $3 O T$ сокращает чистую прибыль существенно. Мы считаем, что это объясняется невозможностью обеспечения эффективной переработки значительных объемов сырья текущими производственными мощностями предприятия. Следовательно, затраты на сырье и материалы кооператива необходимо планировать в пределах 10000 тыс. сомов. Возрастание затрат на оплату труда незначительно влияет на ве- 
личину чистой прибыли. Учитывая, что число работников кооператива не изменялось за последние годы (58 сотрудников), увеличение заработной платы снижает чистую прибыль, но не обеспечивает повышение эффективности работы. Влияние затрат на другие критерии эффективности $B P$ и ОП можем рассчитать аналогичным способом.

Предложенная методика позволяет определить наиболее оптимальный вариант управления эффективностью малого предприятия. Полученные в ходе исследования данные показали справедливость и правильность сделанных прогнозов и доказали эффективность использования искусственного интеллекта в деятельности малых предприятий сельского хозяйства Кыргызской Республики.

Заключение. В результате нашего исследования можно сделать ряд следующих выводов.

1. Выявлена схема взаимосвязи показателей затрат и эффективности исследуемого кооператива.

2. Выполнено рекуррентное моделирование развития сельхозкооператива с применением компьютерной программы, в результате которого рассчитаны прогнозные значения показателей его эффективности.

3. Рассчитаны наиболее естественные значения показателей эффективности сельскохозяйственного кооператива при стабильности внешних условий.

4. Выполнено краткосрочное прогнозирование (на 1 год) и долгосрочное прогнозирование (на 5-10 лет) эффективности исследуемого предприятия.

5. Предложено использовать рекуррентное моделирование как способ поиска оптимальных вариантов тактического и стратегического управления малым предприятием.

6. Установлено, что исследуемый сельскохозяйственный кооператив будет устойчиво работать при случайном изменении макроэкономических показателей в пределах $\pm 20 \%$, а чистая прибыль колеблется в пределах 3200-3800 тыс. сомов.

\section{Список источников}

1. Аверкин А.Н., Гаазе-Рапопорт М.Г., Поспелов Д.А. Толковый словарь по искус- ственному интеллекту. М.: Радио и связь, $1992.256 \mathrm{c}$.

2. Андерсон Т. Статистический анализ временных рядов. М.: Мир, 1976. 757 с.

3. Базиева А.М., Гыязов А.Т. Составление оптимальной структуры управления сельскохозяйственным кооперативом - путь совершенствования эффективности производства // Агропродовольственная экономика. 2016. №5. С. 6-14.

4. Бокс Дж. Анализ временных рядов. Прогноз и управление / Дж. Бокс, Г. Дженкинс. М.: Мир, 1974. Вып. 1. 406 с.

5. McCarthy J. What is Artificial Intelligence? [Electronic resource] / Computer Science Department. Stanford University. Stanford, 2007. 15 p. URL: http://jmc.stanford.edu/articles/whatisai/whatisai.pdf.

6. Дуброва Т.А. Статистические методы прогнозирования. М.: ЮНИТИ-ДАНА, 2003. $133 \mathrm{c}$.

7. Дуброва Т.А. Анализ временных рядов и прогнозирование в системе «Statistica»/ Т. А. Дуброва, Л.П. Бакуменко и др. М.: МЭСИ, 2002. $83 \mathrm{c.}$

8. Лукашин Ю.П. Адаптивные методы краткосрочного прогнозирования временных рядов. М.: Финансы и статистика, 2003. 415 с.

9. Статистическое моделирование и прогнозирование: учеб. пособие / Г. М. Гамбаров, Н. М. Журавель, Ю. Г. Королев и др. / под ред. А.Г. Гранберга. М.: Финансы и статистика, 2000. $340 \mathrm{c}$.

10. Четыркин Е.Н. Статистические методы прогнозирования. М.: Статистика, 1975. 200 с.

11. Юзбасиев М.М. Статистический анализ тенденций и колеблемости / М. М. Юзбасиев, А.М. Манелл. М.: Финансы и статистика, 1998. 207 с.

\section{References}

1. Averkin A.N., Gaaze-Rapoport M.G., Pospelov D.A. Tolkovyj slovar' po iskusstvennomu intellektu [Explanatory dictionary of artificial intelligence]. Moscow: Radio i svjaz', 1992. 256 p. (In Russ.).

2. Anderson T. Statisticheskij analiz vremennyh rjadov [Statistical analysis of time series]. Moscow: Mir, 1976. 757 p. (In Russ.).

3. Bazieva A.M., Gyjazov A.T. Sostavlenie optimal'noj struktury upravlenija 
sel'skohozjajstvennym kooperativom - put' sovershenstvovanija jeffektivnosti proizvodstva [Compilation of the optimal management structure of an agricultural cooperative - a way to improve production efficiency]. Agroprodovol'stvennaja jekonomika [Agro-food economy]. 2016; 5: 6-14. (In Russ.).

4. Boks Dzh. Analiz vremennyh rjadov. Prognoz i upravlenie [Time series analysis. Forecast and management]. Dzh. Boks, G. Dzhenkins. Moscow: Mir, 1974; 1: 406. (In Russ.).

5. McCarthy J. What is Artificial Intelligence? [Electronic resource] / Computer Science Department. Stanford University. Stanford, 2007. 15 p. URL: http://jmc.stanford.edu/articles/whatisai/whatisai.pdf.

6. Dubrova T.A. Statisticheskie metody prognozirovanija [Statistical methods of forecasting]. Moscow: JuNITI-DANA, 2003. 133 p. (In Russ.).

7. Dubrova T.A. Analiz vremennyh rjadov i prognozirovanie v sisteme «Statistica» [Time series analysis and forecasting in the «Statistica» system]. T.A. Dubrova, L.P. Bakumenko et al. Moscow: MJeSI, 2002. 83 p. (In Russ.).

8. Lukashin Ju. P. Adaptivnye metody kratkosrochnogo prognozirovanija vremennyh rjadov [Adaptive methods of short-term forecasting of time series]. Moscow: Finansy i statistika, 2003. 415 p. (In Russ.).

9. Statisticheskoe modelirovanie i prognozirovanie: ucheb. posobie [Statistical modeling and forecasting: textbook]. G.M. Gambarov, N. M. Zhuravel', Ju. G. Korolev et al.; pod red. A. G. Granberga [In A. G. Granberg (eds.)]. Moscow: Finansy i statistika, 2000. 340 p. (In Russ.).

10. Chetyrkin E. N. Statisticheskie metody prognozirovanija [Statistical methods of forecasting]. Moscow: Statistika, 1975. 200 p. (In Russ.).

11. Juzbasiev M.M. Statisticheskij analiz tendencij i koleblemosti [Statistical analysis of trends and fluctuations]. M.M. Juzbasiev, A. M. Manell. Moscow: Finansy i statistika, 1998. 207 p. (In Russ.).

Статья поступила в редакцию 07.09.2021; одобрена после рецензирования 18.09.2021; принята к публикачии 22.09.2021.

The article was submitted on 07.09.2021; approved after reviewing on 18.09.2021; accepted for publication on 22.09.2021.

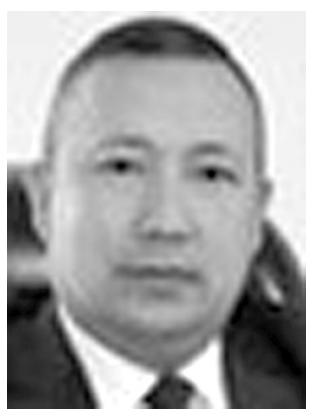

\section{ИНФОРМАЦИЯ ОБ АВТОРАХ}

Гыязов Айдарбек Токторович - доктор экономических наук, профессор, ректор Баткенского государственного университета.

Кыргызстан, г. Баткен, ул. И. Жусупова, 21

Aidarbek T. Giyazov - Doctor of Economic Sciences, Professor, Rector, Batken State University.

21 I. Zhusupov st., Batken, Kyrgyzstan 


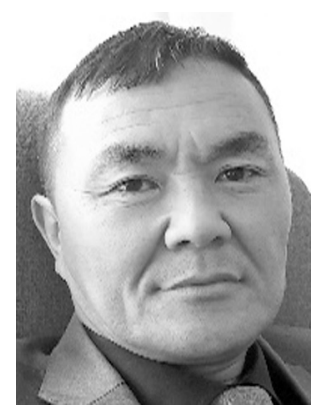

Усонов Муса Мурзапарович - старший преподаватель Баткенского государственного университета.

Кыргызстан, г. Баткен, ул. И. Жусупова, 21

Musa M. Usonov - Senior Lecturer, Batken State University.

21 I. Zhusupov st., Batken, Kyrgyzstan

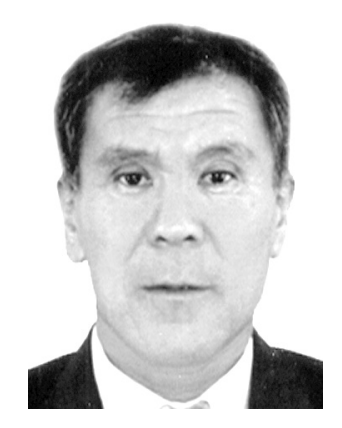

Тагаев Хабибулла Кушакович - старший преподаватель Баткенского государственного университета.

Кыргызстан, г. Баткен, ул. И. Жусупова, 21 versity.

Khabibulla K. Tagaev — Senior Lecturer, Batken State Uni-

21 I. Zhusupov st., Batken, Kyrgyzstan

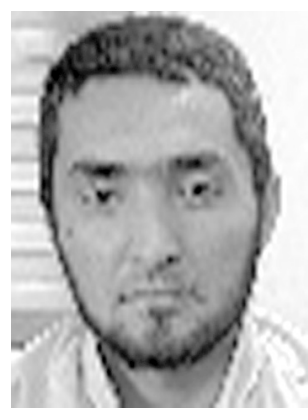

Кадыров Шукурбек Илиясович - старший преподаватель Баткенского государственного университета.

Кыргызстан, г. Баткен, ул. И. Жусупова, 21 versity.

Shukurbek I. Kadyrov — Senior Lecturer, Batken State Uni-

21 I. Zhusupov st., Batken, Kyrgyzstan

Вклад авторов:

Гыязов А. Т. - научное руководство; концепция и методология исследования; итоговые выводы.

Усонов М. М. - разработка концепции исследования; проведении исследования; обработка результатов.

Тагаев Х.К. - проведение исследования; обработка результатов.

Кадыров Ш. И. - доработка текста; итоговые выводы.

Contribution of the authors:

Giyazov A. T. - scientific guidance; research concept and methodology; final conclusions.

Usonov M. M. - development of the research concept; conducting research; processing the results.

Tagaev Kh. K. - conducting research; processing the results.

Kadyrov Sh. I. - revision of the text; final conclusions. 